CLINICAL STUDY

\title{
Leptin administration to overweight and obese subjects for 6 months increases free leptin concentrations but does not alter circulating hormones of the thyroid and IGF axes during weight loss induced by a mild hypocaloric diet
}

Greeshma K Shetty ${ }^{1}$, Giuseppe Matarese ${ }^{2}$, Faidon Magkos ${ }^{1}$, Hyun-Seuk Moon ${ }^{1}$, Xiaowen Liu ${ }^{1}$, Aoife M Brennan ${ }^{1}$, Geetha Mylvaganam $^{1}$, Despina Sykoutri ${ }^{1}$, Alex M DePaoli ${ }^{3}$ and Christos S Mantzoros ${ }^{1,4}$

${ }^{1}$ Division of Endocrinology, Diabetes and Metabolism, Harvard Medical School and Harvard School of Public Health, Beth Israel Deaconess Medical Center, 330 Brookline Avenue, Boston, Massachusetts 02215, USA, ${ }^{2}$ Laboratorio di Immunologia, Istituto di Endocrinologia e Oncologia Sperimentale, Consiglio Nazionale delle Ricerche (IEOS-CNR), Napoli, Italy, ${ }^{3}$ Amgen, Inc., Thousand Oaks, California, USA and ${ }^{4}$ Section of Endocrinology, Boston VA Healthcare System, Boston, Massachusetts, USA

(Correspondence should be addressed to C S Mantzoros at Division of Endocrinology, Diabetes and Metabolism, Harvard Medical School and Harvard School of Public Health, Beth Israel Deaconess Medical Center; Email: cmantzor@bidmc.harvard.edu)

\begin{abstract}
Objective: Short-term energy deprivation reduces leptin concentrations and alters the levels of circulating hormones of the hypothalamic-pituitary-peripheral axis in lean subjects. Whether the reduction in leptin concentration during long-term weight loss in obese individuals is linked to the same neuroendocrine changes seen in lean, leptin-sensitive subjects remains to be fully clarified.

Methods: In this study, 24 overweight and obese adults (16 women and eight men; body mass index (BMI): $\left.27.5-38.0 \mathrm{~kg} / \mathrm{m}^{2}\right)$ were prescribed a hypocaloric diet $(-500 \mathrm{kcal} / \mathrm{day})$ and were randomized to receive recombinant methionyl leptin $(n=18$, metreleptin, $10 \mathrm{mg} /$ day self-injected s.c.) or placebo ( $n=6$, same volume and time as metreleptin) for 6 months.

Results: Metreleptin administration did not affect weight loss beyond that induced by hypocaloric diet alone $(P$ for interaction $=0.341)$ but increased the serum concentrations of total leptin by six- to eight-fold $(P<0.001)$ and led to the generation of anti-leptin antibodies. Despite free leptin concentration $(P$ for interaction $=0.041)$ increasing from $9 \pm 1 \mathrm{ng} / \mathrm{ml}$ at baseline to $43 \pm 15$ and $36 \pm 12 \mathrm{ng} / \mathrm{ml}$ at 3 and 6 months, respectively, changes in circulating hormones of the thyroid and IGF axes at 3 and 6 months were not significantly different in the placebo- and metreleptin-treated groups. Conclusions: Leptin does not likely mediate changes in neuroendocrine function in response to weight loss induced by a mild hypocaloric diet in overweight and obese subjects.
\end{abstract}

European Journal of Endocrinology 165 249-254

\section{Introduction}

The inability to maintain weight loss in the long term (beyond 6 months) (1) likely involves a compensatory decrease in energy expenditure (2). Several alterations in neuroendocrine function induced by weight loss, including changes in circulating hormones of the thyroid hormone and GH/insulin-like growth factor (IGF) axes, have been proposed to underlie this phenomenon (3-6).

Leptin is an adipocyte-secreted hormone with pleiotropic neuroendocrine actions pertaining to energy homeostasis $(7,8)$. Animals and humans with severe hypoleptinemia or complete leptin deficiency, even when obese, have neuroendocrine abnormalities similar to those seen in response to starvation; these abnormalities are alleviated by exogenously administered leptin $(5,9,10)$. We have made similar observations after
3 days of total fasting in healthy lean subjects whose leptin concentration fell well below normal (11) but not in those in whom leptin concentration fell but remained at the low normal range (12). Available information in obese subjects, who are typically hyperleptinemic even when they lose weight, is inconclusive. In one study, replacement doses of recombinant methionyl leptin (metreleptin, formerly known as r-metHuLeptin), administered sequentially after weight loss induced by a very low calorie liquid diet, completely restored the weight loss-induced changes in thyroid hormones (13), whereas pharmacological doses of recombinant leptin during weight loss induced by semi-starvation in another study had no effect on thyroid hormone and IGF1 concentrations (14). The severe calorie restriction (energy intake of 500-800 kcal/day) and accelerated rate of weight loss over a short period of time $(\sim 10 \%$ within $5-10$ weeks) in these studies $(13,14)$ do not 
allow extrapolation of these findings to a more physiological setting, where mild dietary energy restriction slowly induces weight loss over a 6-month period before body weight starts plateauing (1). This is important because the degree of energy deficit not only determines the degree of hypoleptinemia but may also affect weight loss-induced physiological responses to leptin treatment (14-16).

The aim of this study, therefore, was to evaluate the effect of metreleptin treatment (to increase serum leptin concentrations) on the changes in circulating hormones of the thyroid and IGF axes in overweight and obese subjects during weight loss induced by a mild hypocaloric diet over 6 months. Because free leptin is presumed to be the biologically active form of circulating leptin (17), we have developed an in-house assay for measuring, for the first time, free leptin levels after metreleptin or placebo administration in obese subjects during weight loss.

\section{Methods}

\section{Subjects}

This study was a post hoc subset analysis of data from a larger study of 208 obese (body mass index (BMI) $>30 \mathrm{~kg} / \mathrm{m}^{2}$ ) and overweight (BMI $>27 \mathrm{~kg} / \mathrm{m}^{2}$ with one or more comorbidities, including hypertension, dyslipidemia, and glucose intolerance) individuals who participated in a 6-month, double-blind, randomized phase II clinical trial, designed to examine the weightreducing and metabolic effects of metreleptin, that was conducted between 2000 and 2004. Exclusion criteria for the original trial included recent changes in body weight ( $\geq 3 \mathrm{~kg}$ in the past 6 months), diabetes mellitus, HIV infection, hypersensitivity to Escherichia coli, pregnancy, and use of medications. Subjects eligible for the subset analysis $(n=24 ; 16$ women and 8 men; age: $23-67$ years; BMI: $27.5-38.0 \mathrm{~kg} / \mathrm{m}^{2}$ ) were only those who achieved at least moderate and clinically significant weight loss in response to the 6-month dietary intervention ( $\geq 8 \%$ of initial body weight). This allowed for evaluating the role of leptin in regulating hormonal changes independent of the significant, albeit small effect of pharmacological metreleptin administration on weight loss $(14,18)$. The study was approved by the Beth Israel Deaconess Medical Center Institutional Review Board. All subjects provided written informed consent before enrollment.

\section{Experimental protocol}

Subjects were prescribed a hypocaloric diet designed to reduce their daily energy intake by $500 \mathrm{kcal}$ and were advised to follow this reduced calorie diet for the duration of the study. They were randomized (using a $3: 1$ ratio) in a double-blind fashion to receive either metreleptin $(10 \mathrm{mg} /$ day split in two equal doses, which were self-injected s.c. at 0800 and 2000 h) or placebo (same volume and timing as leptin) for 6 months; metreleptin and placebo were supplied by Amgen, Inc. (Thousand Oaks, CA, USA). A total of 18 subjects on metreleptin (half men and half women, age: 23-41 years) and six on placebo (all women, age: $24-67$ years) managed to lose $\geq 8 \%$ of their initial body weight and were included in our analysis. Outcomes were assessed at baseline and after 3 and 6 months of treatment. On each occasion, subjects arrived at the laboratory in the morning, following an overnight fast. Body weight was recorded to the nearest $0.1 \mathrm{~kg}$ and a fasting blood sample $(\sim 20 \mathrm{ml})$ was collected by venipuncture. Serum was separated by centrifugation for $15 \mathrm{~min}$ at $2056 \boldsymbol{g}$ and was stored at $-70{ }^{\circ} \mathrm{C}$ until assayed.

\section{Sample analysis}

Leptin, soluble leptin receptor, TSH, total and free triiodothyronine $\left(\mathrm{FT}_{3}\right)$, total and free thyroxine $\left(\mathrm{FT}_{4}\right)$, IGF 1 , and IGF binding proteins (IGFBPs) 1 and 3 were analyzed by immunoassays as described previously (9). Soluble leptin receptor was measured with a commercially available ELISA (R\&D Systems, Minneapolis, MN, USA) with a sensitivity of $0.057 \mathrm{ng} / \mathrm{ml}$, inter-assay coefficient of variation (CV) $5.3-8.6 \%$, and intra-assay CV 2.2-6.1\%. Serum-free leptin was measured by RIA (Millipore, Billerica, MA, USA) with a sensitivity of $0.5 \mathrm{ng} / \mathrm{ml}$, intra-assay CV 3.4-8.9\%, and inter-assay CV $3.0-6.2 \%$. Serum for all free leptin measurements underwent a pre-incubation in a $37^{\circ} \mathrm{C}$ water bath for $2 \mathrm{~h}$, followed by treatment with equal volume of $\gamma$-polyethylene glycol (PEG; Immucor, Inc., Norcross, GA, USA) for $10 \mathrm{~min}$, vortexing the tubes every 2-5 min. Following incubation, the samples were centrifuged at $585 \boldsymbol{g}$ for $20 \mathrm{~min}$ and the sample was removed without disturbing the pellet for assaying. Reported free leptin values have been corrected for 1:2 dilution by pre-treatment PEG solution. All samples for all hormonal evaluations were run in one assay to eliminate inter-assay variability.

Serum anti-leptin antibodies were determined by a colorimetric sandwich ELISA developed in-house. Briefly, $50 \mu \mathrm{l}$ recombinant human leptin (R\&D Systems, Inc.) at a final concentration of $10 \mu \mathrm{g} / \mathrm{ml}$ in PBS, pH 7.4, were plate-bound to a 96-well ELISA plate (PBI International S.p.A., Milano, Italy). After incubation for $16 \mathrm{~h}$ at $4{ }^{\circ} \mathrm{C}$, the plates were extensively washed with PBS/0.05\% Tween-20, blocked with $200 \mu \mathrm{l}$ PBS/10\% FCS for $2 \mathrm{~h}$, and were repeatedly washed. Diluted sera in PBS-0.05\% Tween-20/10\% FCS (from $1 / 10$ to $1 / 1000$ ) were added at $100 \mu \mathrm{l}$ per well and incubated for $4 \mathrm{~h}$ at room temperature. After five washes, goat anti-human polyvalent immunoglobulins alkaline phosphataseconjugated Abs (Sigma-Aldrich), 1/30 000 diluted in PBS $/ 0.05 \%$ Tween-20/10\% FCS, were added at $100 \mu \mathrm{l}$ per well for $1 \mathrm{~h}$. The reaction was developed with 
Sigma-Fast p-nitrophenyl phosphate (pNPP, alkaline phosphatase substrate; Sigma-Aldrich) and read after $30 \mathrm{~min}$ at $405 \mathrm{~nm}$ in an ELISA plate reader (Bio-Rad Laboratories). Standard curves of anti-leptin antibodies were developed in each assay using an anti-leptin neutralizing MAB generated in our laboratory (971212 $\mathrm{MAB})$. Anti-leptin antibody concentrations were calculated from O.D. values after extrapolation from standard curves of known concentration of anti-leptin antibodies.

\section{Statistical analysis}

Analyses were performed with PASW version 18 (IBM SPSS, Inc., Chicago, IL, USA) and results are presented as mean \pm s.E.M. Data were analyzed using repeated measures ANOVA with time (0 vs 3 vs 6 months) as within-subjects factor and treatment group (placebo versus metreleptin) as between-subjects factor. When significant interactions emerged, the analysis was repeated for each group separately. Post hoc comparisons between time points were carried out by the LSD test. Adjustment for differences between groups in age and sex distributions was performed using analysis of covariance and examining the time-by-sex and timeby-age interactions. A two-tailed $P$ value $<0.05$ was considered statistically significant.

\section{Results}

By design, body weight decreased significantly throughout the 6 -month period $(P<0.001)$, with no significant difference between groups $(P=0.558)$ or interaction with treatment $(P=0.341$; Fig. $1 A)$. There were no time-by-age $(P=0.979)$ and time-by-sex $(P=0.178)$ interactions. Weight loss from baseline was $8.2 \pm 1.3$ and $9.2 \pm 1.1 \%$ in the placebo and metreleptin groups, respectively, at 3 months and $10.2 \pm 1.7$ and 12.7 $\pm 1.2 \%$, respectively, at 6 months $(P=0.642$ at 3 months and $P=0.281$ at 6 months, for the differences between groups).

Significant interactions were detected for serum leptin $(P<0.001)$ and free leptin $(P=0.041)$ concentrations; both increased $(P \leq 0.025)$ in metreleptintreated subjects by 3 months (and remained elevated at 6 months), contrary to placebo-treated subjects $(P \geq 0.2$; Fig. 1B and $\mathrm{C})$. Although the interaction for soluble leptin receptor concentration failed to reach significance $(P=0.107)$, within-group analysis indicated that it increased by $15-20 \%$ after metreleptin $(P=0.003)$ but not after placebo $(P=0.233)$ treatment (Fig. 1D). There were no time-by-age and time-by-sex interactions for serum leptin $(P \geq 0.29)$, free leptin $(P \geq 0.48)$, and soluble leptin receptor $(P \geq 0.46)$. Antileptin antibodies were detected in ten (56\%) metreleptin-treated subjects after 3 and 6 months of treatment; antibody titer concentrations averaged $76 \pm 12$ and $68 \pm 6 \mu \mathrm{g} / \mathrm{ml}$.
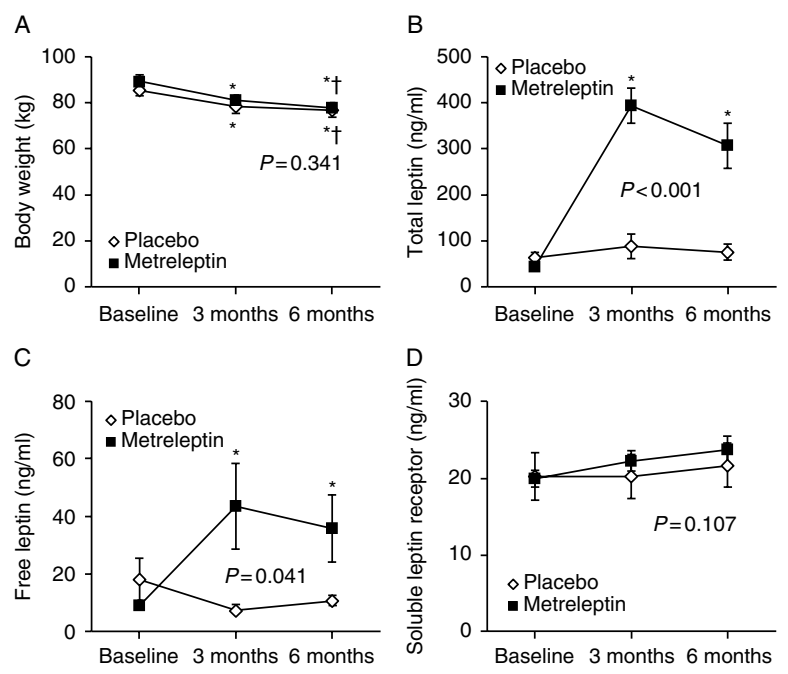

Figure 1 Body weight $(A)$ and serum concentrations of total leptin $(B)$, free leptin $(C)$, and soluble leptin receptor (D) before and after 3 and 6 months of treatment with metreleptin or placebo. Values are mean \pm s.E.M. The $P$ values for the time-by-group interaction from repeated measures ANOVA are shown; symbols represent LSD post hoc tests: *significantly different from value at baseline, $P<0.05 ;{ }^{\dagger}$ significantly different from value at 3 months, $P<0.05$.

Serum IGF1 concentration increased and $\mathrm{FT}_{4}$, total, and $\mathrm{FT}_{3}$ concentrations decreased following hypocaloric diet-induced weight loss (all $P \leq 0.01$ ), whereas the concentrations of IGFBP1, IGFBP 3 , TSH, and total $\mathrm{T}_{4}$ were not altered, in both the leptin- and the placebotreated groups; no significant differences between treatment groups (metreleptin versus placebo) or treatment group-by-time interactions were detected (Table 1). With respect to all measured parameters, there were no significant differences in the hormonal responses to weight loss between subjects with and without anti-leptin antibodies (data not shown), nor were there any significant time-by-age $(P \geq 0.24)$ and time-by-sex $(P \geq 0.13)$ interactions.

\section{Discussion}

In agreement with the previous literature $(3,4)$, we found that weight loss reduced total and $\mathrm{FT}_{3}$ concentrations, reduced $\mathrm{FT}_{4}$ but did not change total $\mathrm{T}_{4}$ concentrations, and did not affect TSH concentration. We also observed a mild increase in IGF1 concentration and no change in IGFBPs, which is to be expected given that obesity is associated with low normal IGF1 concentrations $(3,19)$. Administration of metreleptin in pharmacological doses resulted in supraphysiological total serum leptin levels (the majority was bound to anti-leptin antibodies), but also increased circulating free leptin levels in the high physiological range for obese subjects. Nevertheless, it did not affect nor did it reverse changes in hormones of the thyroid and IGF 
Table 1 Neuroendocrine function before and after 3 and 6 months of treatment with metreleptin or placebo. Values are mean \pm S.E.M.

\begin{tabular}{|c|c|c|c|c|c|c|c|c|c|}
\hline & \multicolumn{2}{|c|}{ Baseline } & \multicolumn{2}{|c|}{ After 3 months } & \multicolumn{2}{|c|}{ After 6 months } & \multicolumn{3}{|c|}{$P$ values } \\
\hline & Placebo & Metreleptin & Placebo & Metreleptin & Placebo & Metreleptin & Time & Treatment & Interaction \\
\hline IGF1 (ng/ml) & $130 \pm 24$ & $158 \pm 11$ & $161 \pm 24^{*}$ & $171 \pm 11^{*}$ & $164 \pm 23^{*}$ & $181 \pm 12^{*}$ & 0.004 & 0.412 & 0.560 \\
\hline IGFBP1 (ng/ml) & $42.6 \pm 21.6$ & $25.2 \pm 6.0$ & $39.5 \pm 20.6$ & $34.9 \pm 6.4$ & $34.1 \pm 15.8$ & $33.0 \pm 5.7$ & 0.814 & 0.567 & 0.409 \\
\hline IGFBP3 (ng/ml) & $7441 \pm 279$ & $7428 \pm 128$ & $7973 \pm 270$ & $7365 \pm 149$ & $7532 \pm 232$ & $7384 \pm 146$ & 0.192 & 0.293 & 0.092 \\
\hline $\mathrm{TSH}(\mu \mathrm{IU} / \mathrm{ml})$ & $1.9 \pm 0.5$ & $2.3 \pm 0.5$ & $2.6 \pm 1.0$ & $2.8 \pm 1.0$ & $2.4 \pm 0.6$ & $2.4 \pm 0.7$ & 0.301 & 0.858 & 0.758 \\
\hline Total $\mathrm{T}_{4}(\mu \mathrm{g} / \mathrm{dl})$ & $5.0 \pm 0.6$ & $5.5 \pm 0.3$ & $5.2 \pm 0.3$ & $5.6 \pm 0.3$ & $5.3 \pm 0.4$ & $5.4 \pm 0.3$ & 0.684 & 0.549 & 0.542 \\
\hline Free $\mathrm{T}_{4}(\mathrm{ng} / \mathrm{dl})$ & $0.95 \pm 0.1$ & $0.93 \pm 0.1$ & $0.81 \pm 0.1^{*}$ & $0.91 \pm 0.1^{*}$ & $0.75 \pm 0.1^{*, \dagger}$ & $0.78 \pm 0.0^{*, \dagger}$ & 0.000 & 0.647 & 0.122 \\
\hline Total $\mathrm{T}_{3}(\mathrm{ng} / \mathrm{dl})$ & $81 \pm 8$ & $82 \pm 3$ & $79 \pm 3$ & $79 \pm 4$ & $72 \pm 4^{*, \dagger}$ & $74 \pm 4^{*, \dagger}$ & 0.011 & 0.894 & 0.888 \\
\hline Free $\mathrm{T}_{3}(\mathrm{ng} / \mathrm{dl})$ & $0.23 \pm 0.02$ & $0.22 \pm 0.01$ & $0.19 \pm 0.01^{*}$ & $0.18 \pm 0.01^{*}$ & $0.19 \pm 0.02^{*}$ & $0.18 \pm 0.01^{*}$ & 0.000 & 0.609 & 0.914 \\
\hline
\end{tabular}

The $P$ values for the effect of time, group, and time-by-group interaction from repeated measures ANOVA are shown; symbols represent LSD post hoc tests: ${ }^{*}$ significantly different from value at baseline, $P<0.05$; ${ }^{\dagger}$ significantly different from value at 3 months, $P<0.05$. IGF, insulin-like growth factor; IGFBP, IGF binding protein; $\mathrm{T}_{3}$, triiodothyronine; $\mathrm{T}_{4}$, thyroxine.

axes in response to moderate weight loss induced by a mild hypocaloric diet for 6 months in overweight and obese individuals. Our results thus suggest that under conditions of weight reduction usually observed in clinical practice (i.e. slow rates of weight loss over a relatively prolonged period of time), leptin is not a likely key factor mediating weight loss-induced changes in endocrine function.

Our findings are in sharp contrast to the observations that exogenous leptin administration in conditions of absolute or relative leptin deficiency in both animals and humans improves neuroendocrine axes $(5,9,10)$ and suggest that leptin has a permissive effect in mediating the endocrine response to energy deprivation, i.e. it is efficacious in hypoleptinemic, leptin-sensitive states but is not efficacious in hyperleptinemic states that remain resistant or tolerant to its effects. We have previously reported that metreleptin substantially blunts the changes in gonadal, adrenal, and thyroid axes in hypoleptinemic male mice (5) and improves reproductive, thyroid, and IGF axes in hypoleptinemic women with exercise-induced hypothalamic amenorrhea (9), i.e. conditions in which acute or prolonged energy deprivation results in circulating leptin levels below normal. Similarly, we have previously reported that preventing the fall in serum leptin in response to shortterm starvation in normal-weight men also prevents some of the starvation-induced neuroendocrine changes, i.e. blunts the suppression of TSH pulsatile secretion and increases $\mathrm{FT}_{4}$ concentration (11). However, in normal-weight women, falling leptin levels to the low physiological range after 3 days of total fasting were associated with much less pronounced neuroendocrine changes, and metreleptin administration in replacement doses had no effect on any component of the thyroid and IGF axes (12). Similar results have been reported for changes in $\mathrm{FT}_{3}, \mathrm{FT}_{4}$, and IGF1 concentrations induced by semi-starvation in obese subjects (14). Our findings confirm and extend these observations, by demonstrating no effect of metreleptin treatment on thyroid and IGF axes in response to modest weight loss induced by mild dietary intake restriction, even when serum leptin increases to supraphysiological levels and free leptin remains within the physiologic range. These findings are at odds with the reported leptin-mediated masking of the fall in circulating total $\mathrm{T}_{3}$ and total $\mathrm{T}_{4}$ concentrations in recently weight-reduced lean and obese subjects in a previous study (13). It is unknown whether this discrepancy is due to a differential effect of leptin during as opposed to after weight loss or whether the apparent effect of leptin in that study (13) was due to time progression and the physiological return of thyroid hormone concentrations to baseline, which may occur within a few weeks or months after starting losing weight $(14,20)$; although, we did not observe this in our placebo-treated subjects.

We found that metreleptin administration led to the generation of anti-leptin antibodies in $56 \%$ of our hyperleptinemic obese subjects, confirming the results from an earlier weight loss clinical trial where such antibodies were detected in some $40-70 \%$ of participants on metreleptin (18). The generation of antibodies against exogenous leptin has also been documented in human subjects with either congenital leptin deficiency or congenital lipodystrophy $(10,21-24)$ and is not unexpected given leptin's s.c. 'immunogenic' administration in relatively high doses over a long time frame and considering that leptin may represent a novel antigen for these patients. Similar to the findings in leptin-deficient subjects (21-23), we recently reported that the antibodies in our obese subjects were not associated with neutralization of leptin's activity in vitro (25). We also detected a trend for increasing levels of circulating soluble leptin receptors (the extracellular cleaved part of the long isoform of the leptin receptor and the main circulating leptin-binding protein). These findings are in line with our earlier short-term observations in lean individuals, in whom both calorie deprivation and pharmacological metreleptin administration independently increased circulating soluble leptin receptors, even though to a much greater extent ( $>$ twofold) (26). Animal in vitro and in vivo data indicate that soluble leptin receptors directly inhibit the transport of leptin across the blood-brain barrier (27). 
In humans, in contrast to total leptin concentration in the cerebrospinal fluid which increases in parallel to its serum concentration over the whole physiological and pharmacological range $(17,28)$, free leptin transport to the brain appears to be saturated as cerebrospinal fluidfree leptin concentration increases disproportionally less with its concentration in serum (17). Despite increasing titers of anti-leptin antibodies and soluble leptin receptor concentrations, we report herein for the first time that the concentration of free leptin (after precipitation of bound leptin) increases in response to long-term pharmacological metreleptin administration in obese subjects. Therefore, even though more than half of the metreleptin-treated subjects developed antibodies, and although the vast majority of circulating leptin in these subjects was bound to anti-leptin antibodies, free leptin also significantly increased, indicating that metreleptin treatment can break through the development of antibodies that are thus not the main reason for the lack of leptin's efficacy.

The reasons why hyperleptinemic obese subjects, contrary to hypoleptinemic or leptin-deficient lean and obese individuals $(9,10)$, do not respond to exogenous leptin administration in terms of endocrine function regulation remain the focus of intense investigation but may be related to underlying leptin resistance or leptin tolerance. We propose, on the basis of these observations, that leptin has a permissive effect to regulate neuroendocrine function, which is pronounced when leptin levels are very low, indicating severe energy deprivation, less pronounced when leptin levels remain within the normal range, and essentially null when leptin levels (despite some degree of weight loss) remain within normal range indicating sufficient energy supplies. This would imply that leptin signaling is saturable but signaling studies in human tissues of interest have not been performed either in vitro or $e x$ vivo.

This study has several limitations. The post hoc selection of subjects who achieved at least modest amounts of weight loss could theoretically raise questions as a potential source of bias, because matching metreleptin and placebo-treated groups for weight loss may have led to the selection of placebo subjects who were more sensitive to the weightreducing effect of the hypocaloric diet (for example, due to lower downregulation of the hypothalamic-pituitaryperipheral axis) or the selection of leptin-treated subjects who were less sensitive to the weight-reducing effect of leptin. Still, this specific study design was deemed necessary in order to focus only on subjects who had the greatest compliance to the dietary prescription and allowed for evaluating the role of leptin without the possible confounding from the large inter-individual variability in weight loss in response to mild caloric restriction (18) and independent of the small albeit significant effect of pharmacological leptin administration on weight loss $(14,18)$.
In summary, we found that pharmacological metreleptin administration does not affect the endocrine responses to weight loss over 6 months in obese subjects enrolled in a usual medical nutrition therapy program for weight loss. These findings clarify that lack of leptin efficacy in the obese is not due to binding of leptin by antibodies and raise the possibility of central resistance or tolerance to leptin, possibly related to a permissive role leptin plays as a hormone primarily signaling energy deprivation in humans. Larger studies are needed to fully elucidate the role of leptin in regulating other neuroendocrine mechanisms in the context of weight loss in the obese.

\section{Declaration of interest}

A M DePaoli was an Amgen employee at the time of the study. The authors have nothing to disclose.

\section{Funding}

This study was an investigator-initiated research protocol and was supported by National Institutes of Health grants F32 DK6455001A1 (to G K Shetty), DK081913, DK79929, DK58785, and AG032030 (to C S Mantzoros); the European Union Ideas Program, ERC-Starting Independent Grant 'LeptinMS' n. 202579 and TelethonJDRF Grant n. GJT08004 (to G Matarese); and a discretionary grant from Beth Israel Deaconess Medical Center. Amgen, Inc. (Thousand Oaks, CA, USA) supplied A-100 r-metHuLeptin (currently 'metreleptin' by Amylin Pharmaceuticals, Inc.) for this study and approved the design of the study but had no role in the study design; conduct of the study; collection, management, analysis, and interpretation of the data; or the preparation, review, or approval of the manuscript.

\section{References}

1 Franz MJ, VanWormer JJ, Crain AL, Boucher JL, Histon T, Caplan W, Bowman JD \& Pronk NP. Weight-loss outcomes: a systematic review and meta-analysis of weight-loss clinical trials with a minimum 1-year follow-up. Journal of the American Dietetic Association 2007 107 1755-1767. (doi:10.1016/j.jada.2007.07.017)

2 Leibel RL, Rosenbaum M \& Hirsch J. Changes in energy expenditure resulting from altered body weight. New England Journal of Medicine 1995332 621-628. (doi:10.1056/NEJM199503093321001)

3 Douyon L \& Schteingart DE. Effect of obesity and starvation on thyroid hormone, growth hormone, and cortisol secretion. Endocrinology and Metabolism Clinics of North America 200231 173-189. (doi:10.1016/S0889-8529(01)00023-8)

4 Roti E, Minelli R \& Salvi M. Thyroid hormone metabolism in obesity. International Journal of Obesity and Related Metabolic Disorders 200024 (Supplement 2) S113-S115.

5 Ahima RS, Prabakaran D, Mantzoros C, Ou D, Lowell B, MaratosFlier E \& Flier JS. Role of leptin in the neuroendocrine response to fasting. Nature $1996 \mathbf{3 8 2}$ 250-252. (doi:10.1038/382250a0)

6 Maccario M, Tassone F, Grottoli S, Rossetto R, Gauna C \& Ghigo E. Neuroendocrine and metabolic determinants of the adaptation of GH/IGF-I axis to obesity. Annales d'Endocrinologie 200263 $140-144$.

7 Dardeno TA, Chou SH, Moon HS, Chamberland JP, Fiorenza CG \& Mantzoros CS. Leptin in human physiology and therapeutics. Frontiers in Neuroendocrinology 201031 377-393. (doi:10.1016/ j.yfrne.2010.06.002)

8 Mantzoros CS. Role of leptin in reproduction. Annals of the New York Academy of Sciences 2000900 174-183. (doi:10.1111/ j.1749-6632.2000.tb06228.x) 
9 Welt CK, Chan JL, Bullen J, Murphy R, Smith P, DePaoli AM, Karalis A \& Mantzoros CS. Recombinant human leptin in women with hypothalamic amenorrhea. New England Journal of Medicine 2004351 987-997. (doi:10.1056/NEJMoa040388)

10 Farooqi IS, Matarese G, Lord GM, Keogh JM, Lawrence E, Agwu C, Sanna V, Jebb SA, Perna F, Fontana S, Lechler RI, DePaoli AM \& O'Rahilly S. Beneficial effects of leptin on obesity, T cell hyporesponsiveness, and neuroendocrine/metabolic dysfunction of human congenital leptin deficiency. Journal of Clinical Investigation 2002110 1093-1103. (doi:10.1172/JCI15693)

11 Chan JL, Heist K, DePaoli AM, Veldhuis JD \& Mantzoros CS. The role of falling leptin levels in the neuroendocrine, and metabolic adaptation to short-term starvation in healthy men. Journal of Clinical Investigation $2003 \mathbf{1 1 1}$ 1409-1421. (doi:10.1172/ JCI200317490)

12 Chan JL, Matarese G, Shetty GK, Raciti P, Kelesidis I, Aufiero D, De Rosa V, Perna F, Fontana S \& Mantzoros CS. Differential regulation of metabolic, neuroendocrine, and immune function by leptin in humans. PNAS 2006103 8481-8486. (doi:10.1073/ pnas.0505429103)

13 Rosenbaum M, Goldsmith R, Bloomfield D, Magnano A, Weimer L, Heymsfield S, Gallagher D, Mayer L, Murphy E \& Leibel RL. Low-dose leptin reverses skeletal muscle, autonomic, and neuroendocrine adaptations to maintenance of reduced weight. Journal of Clinical Investigation 2005115 3579-3586. (doi:10. 1172/JCI25977)

14 Hukshorn CJ, Menheere PP, Westerterp-Plantenga MS \& Saris WH. The effect of pegylated human recombinant leptin (PEG-OB) on neuroendocrine adaptations to semi-starvation in overweight men. European Journal of Endocrinology 2003148 649-655. (doi:10.1530/eje.0.1480649)

15 Hukshorn CJ, van Dielen FM, Buurman WA, WesterterpPlantenga MS, Campfield LA \& Saris WH. The effect of pegylated recombinant human leptin (PEG-OB) on weight loss and inflammatory status in obese subjects. International Journal of Obesity and Related Metabolic Disorders 200226 504-509. (doi:10. 1038/sj.ijo.0801952)

16 Kozlowska L \& Rosolowska-Huszcz D. Leptin, thyrotropin, and thyroid hormones in obese/overweight women before and after two levels of energy deficit. Endocrine 200424 147-153. (doi:10. 1385/ENDO:24:2:147)

17 Brabant G, Horn R, von zur Muhlen A, Mayr B, Wurster U, Heidenreich F, Schnabel D, Gruters-Kieslich A, ZimmermannBelsing T \& Feldt-Rasmussen U. Free and protein bound leptin are distinct and independently controlled factors in energy regulation. Diabetologia 200043 438-442. (doi:10.1007/s001250051326)

18 Heymsfield SB, Greenberg AS, Fujioka K, Dixon RM, Kushner R, Hunt T, Lubina JA, Patane J, Self B, Hunt P \& McCamish M. Recombinant leptin for weight loss in obese and lean adults: a randomized, controlled, dose-escalation trial. Journal of the American Medical Association 1999282 1568-1575. (doi:10. 1001/jama.282.16.1568)

19 Belobrajdic DP, Frystyk J, Jeyaratnaganthan N, Espelund U, Flyvbjerg A, Clifton PM \& Noakes M. Moderate energy restriction-induced weight loss affects circulating IGF levels independent of dietary composition. European Journal of Endocrinology 2010162 1075-1082. (doi:10.1530/EJE-10-0062)

20 Buscemi S, Verga S, Maneri R, Blunda G \& Galluzzo A. Influences of obesity and weight loss on thyroid hormones. A 3-3.5-year follow-up study on obese subjects with surgical bilio-pancreatic by-pass. Journal of Endocrinological Investigation $1997 \mathbf{2 0}$ 276-281.

21 Farooqi IS, Jebb SA, Langmack G, Lawrence E, Cheetham CH, Prentice AM, Hughes IA, McCamish MA \& O'Rahilly S. Effects of recombinant leptin therapy in a child with congenital leptin deficiency. New England Journal of Medicine 1999341 879-884. (doi:10.1056/NEJM199909163411204)

22 Ebihara K, Kusakabe T, Hirata M, Masuzaki H, Miyanaga F, Kobayashi N, Tanaka T, Chusho H, Miyazawa T, Hayashi T, Hosoda K, Ogawa Y, DePaoli AM, Fukushima M \& Nakao K. Efficacy and safety of leptin-replacement therapy and possible mechanisms of leptin actions in patients with generalized lipodystrophy. Journal of Clinical Endocrinology and Metabolism 200792 532-541. (doi:10.1210/jc.2006-1546)

23 Javor ED, Cochran EK, Musso C, Young JR, Depaoli AM \& Gorden P. Long-term efficacy of leptin replacement in patients with generalized lipodystrophy. Diabetes $2005 \quad \mathbf{5 4} \quad 1994-2002$. (doi:10.2337/diabetes.54.7.1994)

24 Beltrand J, Lahlou N, Le Charpentier T, Sebag G, Leka S, Polak M, Tubiana-Rufi N, Lacombe D, de Kerdanet M, Huet F, Robert JJ, Chevenne D, Gressens P \& Levy-Marchal C. Resistance to leptinreplacement therapy in Berardinelli-Seip congenital lipodystrophy: an immunological origin. European Journal of Endocrinology 2010162 1083-1091. (doi:10.1530/EJE-09-1027)

25 Moon HS, Matarese G, Brennan AM, Chamberland JP, Liu X, Fiorenza CG, Mylvaganam GH, Abanni L, Carbone F, Williams CJ, De Paoli AM, Schneider BE \& Mantzoros CS. Efficacy of metreleptin in obese type II diabetics: cellular and molecular pathways underlying leptin tolerance. Diabetes 2011 60 1647-1656. (doi:10.2337/db10-1791)

26 Chan JL, Bluher S, Yiannakouris N, Suchard MA, Kratzsch J \& Mantzoros CS. Regulation of circulating soluble leptin receptor levels by gender, adiposity, sex steroids, and leptin: observational and interventional studies in humans. Diabetes $2002 \mathbf{5 1}$ 2105-2112. (doi:10.2337/diabetes.51.7.2105)

27 Tu H, Kastin AJ, Hsuchou H \& Pan W. Soluble receptor inhibits leptin transport. Journal of Cell Physiology 2008 214 301-305. (doi:10.1002/jcp.21195)

28 Fujioka K, Patane J, Lubina J \& Lau D. CSF leptin levels after exogenous administration of recombinant methionyl human leptin. Journal of the American Medical Association $1999 \mathbf{2 8 2}$ 1517-1518. (doi:10.1001/jama.282.16.1517)

Received 3 May 2011

Accepted 20 May 2011 